\title{
Pituitary abscess: report of two cases and review of the literature
}

\author{
This article was published in the following Dove Press journal: \\ Neuropsychiatric Disease and Treatment \\ 13 June 2017 \\ Number of times this article has been viewed
}

\author{
Yu Liu' \\ Feng Liu $^{2}$ \\ Qi Liang ${ }^{3}$ \\ Yexin $\mathrm{Li}^{4}$ \\ Zhifei Wang ${ }^{5}$ \\ 'Department of Neurosurgery, \\ The Third Xiangya Hospital, \\ Central South University, Changsha, \\ ${ }^{2}$ Department of Neurosurgery, \\ The Third Xiangya Hospital, \\ Central South University, Changsha, \\ ${ }^{3}$ Department of Radiology, The Third \\ Xiangya Hospital, Central South \\ University, Changsha, ${ }^{4}$ Department of \\ Neurosurgery, The Central Hospital \\ of Shaoyang, Shaoyang, ${ }^{5}$ Department \\ of Neurosurgery, The Third Xiangya \\ Hospital, Central South University, \\ Changsha, Hunan, People's Republic \\ of China
}

Correspondence: Zhifei Wang

Department of Neurosurgery,

The Third Xiangya Hospital, Central

South University, No. 138 Tongzipo

Road, Yuelu District, Changsha, Hunan,

People's Republic of China

$\mathrm{Tel}+8673188618218$

Fax +8673 I 886। 82I8

Email doctorwangzhifei@।63.com

\begin{abstract}
Pituitary abscess is a rare but critical disorder caused by an infectious process where purulent material accumulates inside the sella turcica. Since symptoms, signs and radiographic characteristics of pituitary abscess are similar to several other pituitary lesions, correct diagnosis before surgery is challenging. In this article, two cases of pituitary abscess treated in our department are reported, followed by a literature review. In these two cases, both patients presented with intermittent fever. Magnetic resonance imaging revealed a suprasellar lesion with rim enhancement after contrast injection. After transsphenoidal surgery, the diagnosis of pituitary abscess was confirmed. The patients were then given antibiotic treatment and recovered fully in less than 2 months. Findings of this article support timely diagnosis and proper treatment including transsphenoidal surgery and antibiotic therapy for pituitary abscess, leading to lower mortality rates and higher probability of pituitary hormone function recovery.
\end{abstract}

Keywords: pituitary abscess, transsphenoidal resection, antibiotic therapy, diagnosis

\section{Introduction}

Pituitary abscess (PA) is a rare intracranial mass with high mortality, ${ }^{1}$ which explains less than $1 \%$ of all pituitary disease. ${ }^{2}$ In most cases, pathogens are not clear. Its treatment is mainly surgical, combined with the use of antibiotics. ${ }^{3}$ It may occur either as a primary disease or as a result of infection such as sphenoiditis and meningitis. ${ }^{4}$ The clinical manifestations of PA are similar to other pituitary lesions. Because of the rarity of PA and the non-specific symptoms, it is difficult to make a diagnosis before surgery. ${ }^{5}$ Here, we report two cases of PA. Written informed consent has been provided by both patients to have their case details and any accompanying images published.

\section{Case series Case I}

A 37-year-old man presented with intermittent fever for 2 months. Upon admission, the patient was given antibiotic over a 5 day period. Each time after antibiotic treatment his body temperature returned to a normal level. Nevertheless, upon stopping the antibiotic therapy he became febrile again. He had no medical history and was not taking any regular medication, other than antibiotics for his fever.

On clinical examination, his temperature was $39^{\circ} \mathrm{C}$. Neurological examination revealed bitemporal hemianopsia without meningeal signs. Breathing sounds were normal and the abdomen was soft with no mass.

Examination of routine blood work showed mildly high white cell count $\left(12.13 \times 10^{9} / \mathrm{L}\right.$ with $56.8 \%$ neutrophils). Laboratory investigation of inflammatory 
markers, showed elevated erythrocyte sedimentation rate (ESR) of $31 \mathrm{~mm} / \mathrm{h}$ (normal: $0-15 \mathrm{~mm} / \mathrm{h}$ ), and elevated hypersensitive c-reactive protein (HCRP) levels of $5 \mathrm{mg} / \mathrm{L}$ (normal: 0-3 mg/L). Examination of the cerebrospinal fluid (CSF) showed increased protein levels of $787 \mathrm{mg} / \mathrm{L}$ (normal: $150-450 \mathrm{mg} / \mathrm{L}$ ), low glucose levels of $1.93 \mathrm{mmol} / \mathrm{L}$ (normal: $2.5-4.5 \mathrm{mmol} / \mathrm{L})$ and high white cell count $\left(170 \times 10^{6} / \mathrm{L}\right.$ with $80 \%$ neutrophils). No pathogen was isolated from blood or CSF cultures. A routine urine test indicated a urine-specific gravity of 1.010 and no signs of infection. Urinary excretion was 3 to $3.5 \mathrm{~L} / 24 \mathrm{~h}$. Hormonal evaluation revealed elevated serum prolactin (PRL) levels of $34.9 \mathrm{ng} / \mathrm{mL}$ (normal 4.13-18.40), decreased serum thyroid-stimulating hormone
(TSH) of $0.115 \mu \mathrm{IU} / \mathrm{mL}$ (normal: $0.35-5.5$ ) with normal free thyroxine (fT4) of $0.82 \mathrm{ng} / \mathrm{dL}$ (normal: $0.8-1.76 \mathrm{ng} / \mathrm{dL}$ ), and a low morning serum cortisol of $0.819 \mu \mathrm{g} / \mathrm{dL}$ (normal: 6.2-19.4 $\mu \mathrm{g} / \mathrm{dL}$ ) with normal adrenocorticotropic hormone (ACTH) of 19 (normal: 5-50 pg/mL).

Magnetic resonance imaging (MRI) scan showed a more marked thickening of the stalk and a sellar mass measuring $1.6 \times 1.4 \times 1.3 \mathrm{~cm}$ with suprasellar extension. After administration of gadolinium, there was a partial rim enhancement appearance of the lesion on T1-weighted images. The pituitary mass had smooth borders and it compressed the optic chiasm. The patient was diagnosed with possible pituitary adenoma (Figure $1 \mathrm{~A}$ and $\mathrm{B})$.
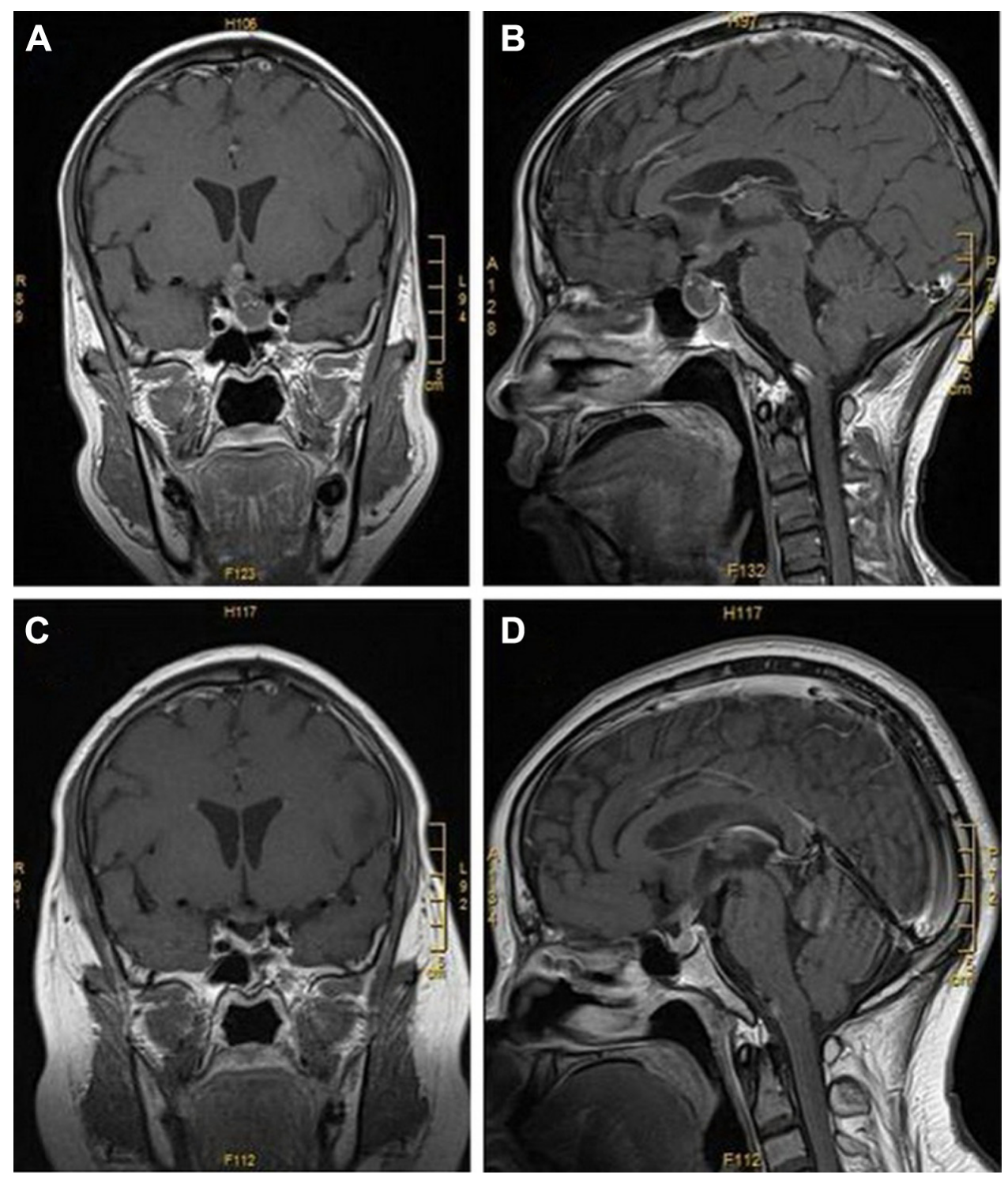

Figure I Preoperative TI-weighted coronal (A) and sagittal (B) images after intravenous gadolinium contrast administration demonstrated a suprasellar partial rim enhancing the mass. Six months after surgery TI-weighted coronal (C) and sagittal (D) images after intravenous gadolinium contrast administration revealed resolution of the pituitary abscess after surgery. 
Empirical antibiotic therapy with intravenous ceftriaxone and hydrocortisone replacement therapy were given to the patient. Thirty-five days following intravenous antibiotics, the patient's temperature, examination of routine blood work, and CSF were all at a normal level. Transsphenoidal resection was performed subsequently. Intraoperatively, a significant amount of yellowish pus was encountered upon surgical incision of the dura mater that forms the capsule of the pituitary gland. The pus was drained and samples were sent for histological analysis and culture. The pituitary gland was found to be intact after the removal of the lesion. No pathogen was isolated and the pathology showed benign anterior pituitary tissue with marked lymphoplasmacytic inflammation.

After the diagnosis of PA, antibiotic treatment continued. The patient was treated with ceftriaxone (Shanghai Roche Pharmaceutical Co., Ltd, Shanghai, People's Republic of China) and teicoplanin (Sanofi-aventis S.p.A, Milano, Italy) intravenously for 2 weeks and oral antibiotic therapy for 4 weeks. Postoperatively, the patient was afebrile, but he developed polyuria ( $>6 \mathrm{~L}$ per day) and was treated with desmopressin ( $0.3 \mathrm{mg}$ orally thrice daily). Postoperative MRI demonstrated a complete removal of the intrasellar mass (Figure $1 \mathrm{C}$ and D).

Two months after surgery, the endocrine laboratory test results were all normal. Visual field examination was normal and there was no bitemporal hemianopsia. Hydrocortisone was discontinued and he was prescribed desmopressin (Ferring Pharmaceuticals Inc., Parsippany, NJ, USA) once daily.

\section{Case 2}

A 36-year-old man with no significant past medical history was investigated for headache and intermittent fever lasting for 1 month. He did not receive antibiotic treatment for his fever prior to admission.

At the time of admission he was afebrile. There were no meningeal signs and no neurological or cranial nerve deficits. Visual evaluation was normal.

Routine blood test, ESR, HCRP, PRL, ACTH and routine urine tests were all within the normal range, apart from a decrease in the level of TSH $(0.271 \mu \mathrm{IU} / \mathrm{mL}$, normal: $0.35-5.5 \mu \mathrm{IU} / \mathrm{mL})$, fT4 $(0.75 \mathrm{ng} / \mathrm{dL}$, normal: $0.8-1.76 \mathrm{ng} / \mathrm{dL})$, and morning serum cortisol $(1.022 \mu \mathrm{g} / \mathrm{dL}$, normal: $6.2-19.4 \mu \mathrm{g} / \mathrm{dL}$ ).

A brain MRI of hypothalamo-pituitary area revealed $1.2 \times 1.2 \times 1.3 \mathrm{~cm}$ mass which had isointense signal in T1-weighted images and hyperintense signals in T2-weighted images with peripheral rim enhancement after administration of gadolinium. An initial diagnosis of PA was considered (Figure 2A and B).

The patient underwent endoscopic transsphenoidal surgery. Upon dura incision, a yellowish purulent material was found (Figure 3). After evacuating the abscess, the pituitary was found preserved intact. A culture of the pus was positive for Staphylococcus aureus. Histological examination revealed fibrocollagenous tissue with infiltration by lymphoplasmacytoid cells.

After surgery the patient was given intravenous ceftriaxone and teicoplanin for 2 weeks. Afterwards, oral antibiotic therapy was continued for another 4 weeks. There were no postoperative complications. Postoperative MRI showed no irregular changes post-surgery and complete evacuation of the abscess (Figure 2C and D).

Six weeks after surgery, the laboratory investigation results were all within the normal range. The patient recovered fully. Hormone replacement treatment was discontinued.

\section{Discussion}

PAs are uncommon, with only about 270 cases globally reported to date. ${ }^{6} \mathrm{PA}$ has an incidence of $1 \%$ among pituitary lesions. ${ }^{2,6-9}$

PA may occur de novo, such as in our patients, in a previously healthy normal pituitary gland in $70 \%$ of cases. ${ }^{2,10}$ It also can occur secondarily to a pre-existing lesion in the pituitary region, such as pituitary adenoma, craniopharyngioma, or Rathke's cleft cyst. ${ }^{11-13}$ Moreover, immunosuppression, previous irradiation or surgical procedures to the pituitary gland are also known risk factors for PA., ${ }^{7,9}$ In most cases of PA, no apparent causes are generally found. ${ }^{7}$

Our patients presented with fever, headache, visual disorder and symptoms of pituitary hormone deficiency. Anterior pituitary hypofunction is the most common symptom of PA, such as anorexia, weakness, amenorrhea, vomiting, and hypogonadism. In one series of 33 patients, 28 reported anterior pituitary hypofunction symptom. ${ }^{7}$ Headache is the second-most common symptom. In another series of 66 patients, 46 reported a headache. ${ }^{6}$ Visual disorders, such as hemianopsia, are also commonly observed. In one series ${ }^{14}$ $57 \%$ of patients with PA presented with visual disorders. Central diabetes insipidus has an incidence of $41.4 \%-69.7 \%$ among PA patients. ${ }^{4,7}$ However, it is uncommon for pituitary adenomas to present with diabetes insipidus. ${ }^{15}$ Heary reported that diabetes insipidus was only present in $10 \%$ of pituitary adenoma cases. ${ }^{16}$ Therefore, diabetes insipidus in the diagnosis of PA is of great significance. Fever with signs of meningeal irritation was inspected in only $25 \%$ of patients. ${ }^{9}$ 

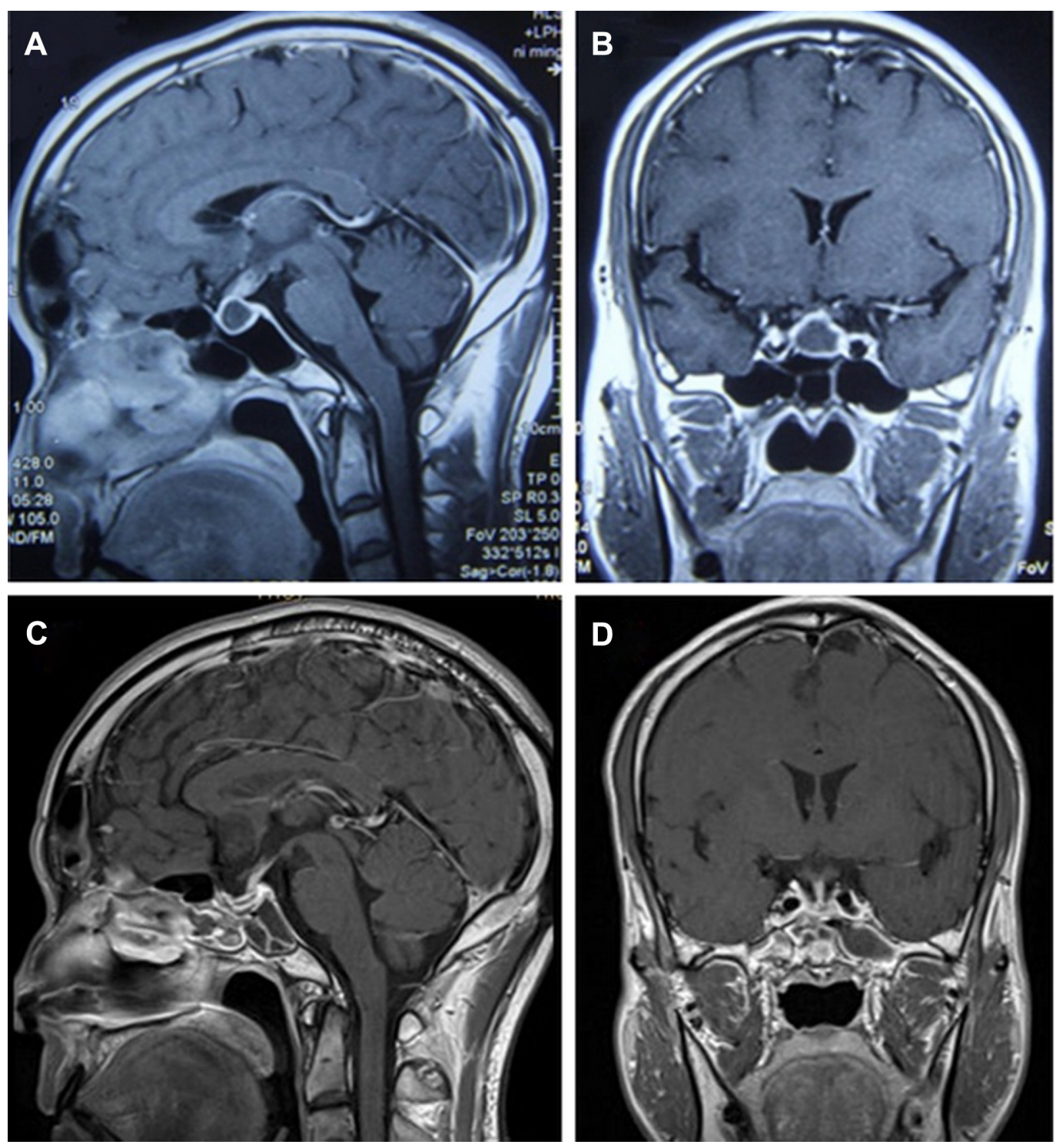

Figure 2 Preoperative TI-weighted coronal (A) and sagittal (B) images after intravenous gadolinium contrast administration revealed a suprasellar rim enhancing mass. Five days after surgery TI-weighted coronal (C) and sagittal (D) images after intravenous gadolinium contrast administration revealed resolution of the pituitary abscess after surgery.

Microorganisms such as Staphylococcus and Streptococcus are the most common isolated pathogens from pituitary abscess. ${ }^{9}$ Additionally, plenty of different microorganisms have been seen in surgical cultures from PA such as Neisseria spp., Micrococcus, Citrobacter spp., Escherichia coli, Brucella, Salmonella, Corynebacterium, and Mycobacterium. ${ }^{9}$ However, Aspergillus fumigatus was most frequently noted in cases of secondary PA. ${ }^{6}$ In our first case, no infectious agent was isolated, which might be due to previous antibiotic treatment.

MRI is one of the most effective imaging approaches for pituitary lesions. Typical features of PA include a single cystic or partially cystic mass that appears hypointense in T1-weighted and hyperintense in T2-weighted imaging, and shows rim enhancement after gadolinium injection. ${ }^{7,17}$ However, in one series only $66.7 \%$ of the patients exhibited such typical features on MRI. ${ }^{6}$ Our patients presented with a rim enhancing suprasellar mass, which was not specific for PA. On the basis of these observations, MRI has limitations in recognizing PA from other pathology of the suprasellar region.

Transsphenoidal excision (TSS) and antibiotic therapy are the main treatment for PA., ${ }^{4,6} 7$ Transsphenoidal resection is preferred over craniotomy, as TSS has the advantages of efficacy, safety, and minimal invasiveness and craniotomy can cause infectious substances to spill into cerebrospinal fluid. ${ }^{4,12}$ Antibiotic therapy should be instituted for approximately 4-6 weeks. It is indicated that empirical treatment should be 


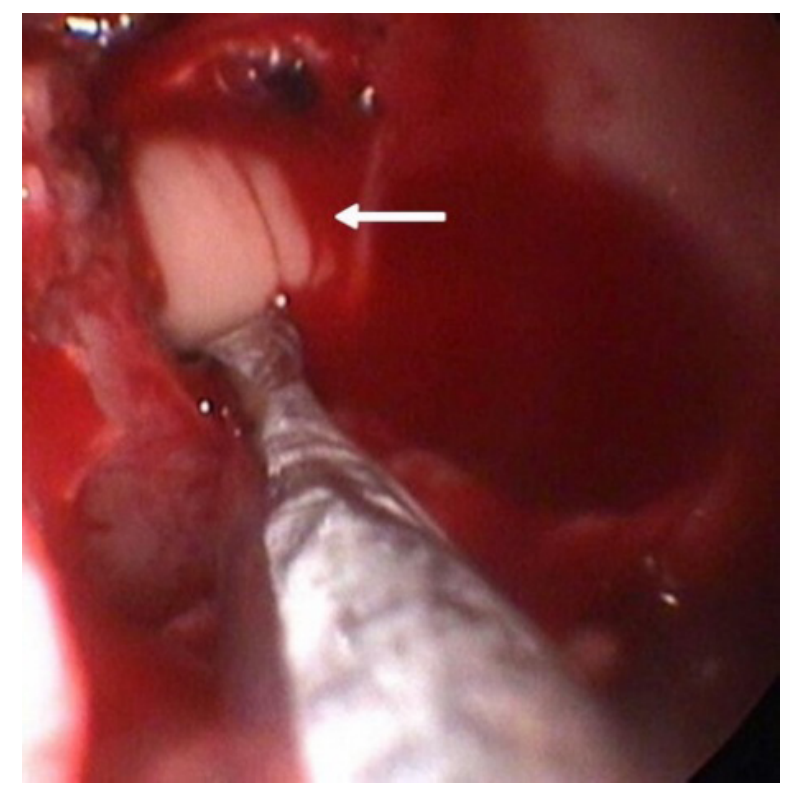

Figure 3 Intraoperative picture of transsphenoidal excision showing a significant amount of yellowish pus (white arrow) that was encountered upon surgical incision of the dura mater that forms the capsule of the pituitary gland.

given to the patients who are waiting for microbiology and histological confirmation. ${ }^{9,12}$ Hormone replacement therapy is needed based on pituitary hormone deficiency. ${ }^{12,18}$ Our patients received antibiotic and hormone replacement therapy after transsphenoidal excision.

Timely diagnosis and appropriate treatment of PA typically result in low mortality, and patients may eventually have a good quality of life. In one series of 66 patients, $81.8 \%$ of patients had fully recovered, $12.1 \%$ of patients had undergone at least one operation for recurrence, and only one patient had died, 4 years after the operation. ${ }^{6}$ Treatment is effective for typical symptoms such as fever, headache and visual changes. In one series of 24 patients, headaches and visual problems were alleviated for over $90 \%$ and $75 \%$ of patients, respectively. ${ }^{9}$ Two patients had completely recovered from fever, headache and bitemporal hemianopsia. As seen in our patients, proper postoperative hormone replacement is needed considering the high rate of hypopituitarism $(62.5 \%)$ even after surgery. ${ }^{9}$

In conclusion, these case reports emphasize the importance of timely diagnosis and treatment of PA. Because of similarities in clinical symptoms, signs, imaging and laboratory findings with other sellar lesions, PA is highly difficult to diagnose before surgery. Therefore, the diagnosis of PA should be considered when patients have fever, headache and signs of pituitary dysfunction, or for patients with sellar lesion presenting with signs of meningeal inflammation. Appropriate surgery and medical treatment leads to a lower mortality rate and higher probability of pituitary hormone function recovery.

\section{Acknowledgment}

This work was supported by the National Natural Science Foundation of China (81602211).

\section{Disclosure}

The authors report no conflicts of interest in this work.

\section{References}

1. Safaee MM, Blevins L, Liverman CS, Theodosopoulos PV. Abscess formation in a nonfunctioning pituitary adenoma. World Neurosurgery. 2016;90:703.e15-e718.

2. Jain KC, Varma A, Mahapatra AK. Pituitary abscess: a series of six cases. British Journal of Neurosurgery. 1997;11(2):139-143.

3. Dechambenoit G, Datie A, Grunitzky EK, et al. Abcés hypophysaire traité médicalement [Pituitary abscess, treated by medication]. Rev Neurol (Paris). 1993;149(10):567-571. French.

4. Zhang X, Sun J, Shen M, et al. Diagnosis and minimally invasive surgery for the pituitary abscess: a review of twenty nine cases. Clin Neurol Neurosurg. 2012;114(7):957-961.

5. Walia R, Bhansali A, Dutta P, et al. An uncommon cause of recurrent pyogenic meningitis: pituitary abscess. BMJ case reports. 2010; 2010:bcr0620091945.

6. Gao L, Guo X, Tian R, et al. Pituitary abscess: clinical manifestations, diagnosis and treatment of 66 cases from a large pituitary center over 23 years. Pituitary. 2017;20(2):189-194.

7. Liu F, Li G, Yao Y, et al. Diagnosis and management of pituitary abscess: experiences from 33 cases. Clin Endocrinol. 2011;74(1):79-88.

8. Dutta P, Bhansali A, Singh P, Kotwal N, Pathak A, Kumar Y. Pituitary abscess: report of four cases and review of literature. Pituitary. 2006; 9(3):267-273.

9. Vates GE, Berger MS, Wilson CB. Diagnosis and management of pituitary abscess: a review of twenty-four cases. J Neurosurg. 2001; 95(2):233-241.

10. Awad AJ, Rowland NC, Mian M, Hiniker A, Tate M, Aghi MK. Etiology, prognosis, and management of secondary pituitary abscesses forming in underlying pituitary adenomas. J Neurooncol. 2014;117(3): 469-476.

11. Obrador S, Blazquez MG. Pituitary abscess in a craniopharyngioma. Case report. J Neurosurg. 1972;36(6):785-789.

12. Ciappetta P, Calace A, D’Urso PI, De Candia N. Endoscopic treatment of pituitary abscess: two case reports and literature review. Neurosurg Rev. 2008;31(2):237-246.

13. Wolansky LJ, Gallagher JD, Heary RF, et al. MRI of pituitary abscess: two cases and review of the literature. Neuroradiology. 1997;39(7) 499-503.

14. Domingue JN, Wilson CB. Pituitary abscesses. Report of seven cases and review of the literature. J Neurosurg. 1977;46(5):601-608.

15. Askenasy HM, Israeli J, Karny H, Dujovny M. Intrasellar abscess simulating pituitary adenoma. Neurochirurgia. 1971;14(1):34-37. Available from: https://www.thieme-connect.de/DOI/DOI?10.1055/s0028-1090553. Accessed June 02, 2017.

16. Heary RF, Maniker AH, Wolansky LJ. Candidal pituitary abscess: case report. Neurosurgery. 1995;36(5):1009-1012.

17. Connor SE, Penney CC. MRI in the differential diagnosis of a sellar mass. Clin Radiol. 2003;58(1):20-31.

18. Karagiannis AK, Dimitropoulou F, Papatheodorou A, Lyra S, Seretis A, Vryonidou A. Pituitary abscess: a case report and review of the literature. Endocrinol Diabetes Metab Case Rep. 2016;2016:160014. 


\section{Publish your work in this journal}

Neuropsychiatric Disease and Treatment is an international, peerreviewed journal of clinical therapeutics and pharmacology focusing on concise rapid reporting of clinical or pre-clinical studies on a range of neuropsychiatric and neurological disorders. This journal is indexed on PubMed Central, the 'PsycINFO' database and CAS,

and is the official journal of The International Neuropsychiatric Association (INA). The manuscript management system is completely online and includes a very quick and fair peer-review system, which is all easy to use. Visit http://www.dovepress.com/testimonials.php to read real quotes from published authors.

Submit your manuscript here: http://www.dovepress.com/neuropsychiatric-disease-and-treatment-journal 